\title{
Public Health Informatics: An Essence for Improving Public Health in Developing Nations
}

Paudel R

\begin{abstract}
Department of Community Medicine and Public Health Maharajgunj Medical Campus, Institute of Medicine, TU, Nepal
\end{abstract}

\section{Introduction}

Public Health Informatics has been defined as the systematic application of information and computer science and technology to public health practice, research, and learning. It is one of the sub-domains of Biomedical Informatics. In the United States and developed countries, public health informatics is practiced by individuals in public health agencies at the federal and state levels and in the larger local health jurisdictions. However, in developing countries, use of public health informatics is still behind. Additionally, research and training in public health informatics takes place at a variety of academic institutions. Improvements in the health status of communities depend on effective public health and healthcare infrastructures. These infrastructures are increasingly electronic and tied to the internet. Incorporating emerging technologies into the service of the community has become a required task for every public health leader. (1)

Public health informatics is primarily an engineering discipline undergirded by science and oriented to the accomplishment of specific tasks. The scope of public health informatics includes the conceptualization, design, development, deployment, refinement, maintenance, and evaluation of communication, surveillance, and information systems relevant to public health. It requires the application of knowledge from numerous disciplines, particularly information science, computer science, management, organizational theory, psychology, communications, political science, and law. Its practice must also incorporate knowledge from the other fields that contribute to public health (e.g., epidemiology, microbiology, toxicology, statistics, demography and health policy management etc.). Although public health informatics draws from multiple scientific and practice domains, computer science and information science are its primary underlying disciplines. Computer science, the theory and application of automatic data processing machines, includes hardware and software design, algorithm development, computational complexity, networking and telecommunications, pattern recognition, and artificial intelligence. Information science encompasses the analysis of the structure, properties, and organization of information, information storage and retrieval, information system and database architecture and design, library science, project management, and organizational issues such as change management and business process reengineering. $(2,3)$

\section{Commencement of 'Public Health Informatics'}

Before the advent of the internet, public health data, like other healthcare and business data, were collected on paper forms and stored centrally at the relevant public health agency. If the data were to be computerized they required a distinct data entry process, were stored in the various file formats of the day and analyzed by mainframe computers using standard batch processing. (4) One of the first publications to establish and define "public health informatics" was "Public Health Informatics: How Information-Age Technology Can Strengthen Public Health", an article authored by Andrew Friede, Henrik L. Blum and Mike McDonald. Published in the Annual Review of Public Health in 1995, the paper introduced public health informatics as "the science of applying Information-Age technology to serve the specialized needs of public health." Although the term "Information Age", like the ubiquitous "Information Superhighway", has mostly fallen out of use since the paper was written, the authors' fundamental definition of public health informatics is as relevant and timely now as when it was written: "The application of information science and technology to public health practice and research to support the mission of disease prevention and health promotion". (5)

Since the beginning of the World Wide Web, public health agencies with sufficient information technology resources have been transitioning to web-based collection of public health data, and, more recently, to automated messaging of the same information. In the years roughly 2000 to 2005 the Centers for Disease Control and Prevention, under its National Electronic Disease Surveillance System (NEDSS), built and provided free to states a comprehensive web and message-based reporting system called the NEDSS Base System (NBS). Since about 2005, the CDC has promoted the idea of the Public Health Information Network to facilitate the transmission of data from various partners in the health care industry and elsewhere (hospitals, clinical and environmental laboratories, doctors' practices, pharmacies) to local health agencies, then to state health agencies, and then to the CDC. At each stage the entity must be capable of receiving the data, storing it, aggregating it appropriately, and transmitting

CORRESPONDENCE : Rajan Paudel, Faculty, Department of Community Medicine and Public Health, Maharajgunj

Medical Campus, Institute of Medicine, TU, Nepal. Email: paudel.rajan@gmail.com 
it to the next level. A typical example would be infectious disease data, which hospitals, labs, and doctors are legally required to report to local health agencies; local health agencies must report to their state public health department; which the states must report in aggregate form to the CDC. Among other uses, the CDC publishes the Morbidity and Mortiality Weekly Report (MMWR) based on these data acquired systematically from across the United States. (6)

\section{Improving quality and increasing efficiency of health care services}

In developed economies, there is increasing evidence, documented by systematic reviews, that information and communication technology can improve the quality and safety of health care while reducing its cost. (7) One of the challenges to implementing health information and communication technology is the need for a skilled workforce that understands health care, information and communication technology, and the people and organizational challenges involved. (8) In developing countries, the use of public health informatics can improve the health of people very quickly through the application infollowing areas:

\section{i. Promoting health of people}

The primary focus of public health informatics should be on applications of information science and technology that promote the health of people. As a discipline, public health focuses on the health of the population and the community, as opposed to that of the individual patient. In the health care setting, the major unit of attention is an individual with a specific disease or condition. In public health, consideration for the community as the patient may require "treatment" such as quarantine or disclosure of the disease status of an individual to prevent further spread of illness. It also requires attention to environmental factors (e.g., water quality and automotive safety) that affect the health risk of entire populations rather than specifically identifiable individuals. (2)

\section{ii. Preventing disease and injuries by altering environment}

The major focus of public health informatics should be on applications of information science and technology that prevent disease and injury by altering the conditions or the environment that put people at risk. Public health emphasizes the prevention of disease and injury versus intervention after the problem has already occurred. Although notable exceptions exist, traditional health care largely treats individuals who present with a disease, while public health seeks to avoid the conditions that led to the disease in the first place. (2)

\section{iii. Exploring the potential for prevention at all vulnerable points in the causal chains}

Public health informatics applications should explore the potential for prevention at all vulnerable points in the causal chains leading to disease, injury, or disability; applications should not be restricted to particular social, behavioral, or environmental contexts. In public health, the nature of a given preventive intervention is not predetermined by professional discipline, but rather by the effectiveness, expediency, cost, and social acceptability of intervening at various potentially vulnerable points in a causal chain leading to disease, injury, or disability. Public health interventions have included, for example, legislatively mandated housing and building codes, solid waste disposal and wastewater treatment systems, smoke alarms, fluoridation of municipal water supplies, and removal of lead from gasoline. Contrast this with the modern health care system, which generally accomplishes its mission through clinical and surgical encounters. While some of these encounters can properly be considered public health measures (e.g., vaccination), public health action is not limited to the clinical encounter. (2)

\section{iv. Reflecting the governmental context}

As a discipline, public health informatics should reflect the governmental context in which public health is practiced. Much of public health operates through government agencies that require direct responsiveness to legislative, regulatory, and policy directives, careful balancing of competing priorities, and open disclosure of all activities. In addition, some public health actions involve authority for specific (sometimes coercive) measures to protect the community in an emergency. Examples include medication or food recalls, closing down a restaurant or contaminated pool or lake, and changes to immunization policy. (2)

\section{v. Research, Evaluation and Practices}

Although public health informatics shares with the disciplines of clinical and bioinformatics, themajor focus of the public health on prevention, on communities rather than individuals, on surveillancefor disease and injury, and on longitudinal analysis present unique opportunities for research, evaluation, and best practices. Public health informatics research helps set priorities for resources and ensure that new ideas are adequately tested prior to implementation. A research agenda must be developed that focuses on local, regional, and national activities and addresses short and long-term needs. The public health informatics research agenda should concentrate on areas that are unique to public health concerns and areas that could have a substantial impact. Whenever possible and appropriate, existing medical informatics knowledge and techniques should be reviewed and used. A practical way to foster research and communication is to consistently add an informatics component to the many existing public health research grant applications. (9)

It is important to identify and develop the skills, training, and competencies consistent with local cultures, 
languages, and health systemsthat will be needed to realize the full benefits of Public Health Informatics (10) and more importantly it is applied in developing nations.

\section{Conclusions}

Information and communication technology can be used to improve the quality and safety of health care services and to lower costs. But in developing countries, there is an inadequate supply of skilled individuals who have the technical skills to use this technology to improve health care, however it is not known what size of workforce will be required. Individuals, care providers, and public health agencies can all benefit through the adoption of new information systems, use of electronic methods for disease surveillance, and reformation of outmoded processes. However, realizing the benefits will be neither easy nor inexpensive. Technological innovation brings the promise of new ways of improving health. Individuals have become more involved in knowing about, and managing and improving, their own health through internet access. Similarly, healthcare providers are transforming the ways in which they assess, treat, and document patient care through their use of new technologies. Technology itself will not be enough; they must be understood and managed by those committed professionals to improving community health status. Public health officials will have to understand basic principles of information resource management in order to make the appropriate technology choices that will guide the future.

\section{References}

1. Ross DA, Hinman AR and Foege WH. Public Health Informatics and information system. Springer- Verlag New York, Inc, USA. 2003: ISBN 0-387-95474-0

2. A. Friede, H.L. Blum and M. McDonald. Public Health Informatics: How Information Age Technology Can Strengthen Public Health. Annual Review of Public Health,1995. 16:239-252

3. Yasnoff WA., O'Carroll PW, Koo D, Linkins RW et all. Public Health Informatics: Improving and Transforming Public Health in the Information Age. J Public Health Management Practice, 2000. 6(6):67-75

4. Ross DA, Hinman AR, Saarlas K, and Foege WH. Public Health Informatics and Information Systems. Oct 16, 2002: ISBN 0387-95474-0

5. History of Public Health Informatics.Available from http:// www.phii.org/about/history.Accessed in 1 August 2012.

6. Olmeda, Christopher J. Information Technology in Systems of Care. Delfin Press. 2000: ISBN 978-0-9821442-0-6

7. Goldzweig CL, Towfigh A, Maglione M, Shekelle PG. Costs and benefits of health information technology: new trends from the literature. Health Aff (Millwood), 2009. 28(2):282-93.

8. Garg AX, Adhikari NKJ, McDonald H, Rosas-Arellano MP, Devereaux PJ, Beyene J, et al. Effects of computerized clinical decision support systems on practitioner performance and patient outcomes: a systematic review. JAMA,2005.293:1223-38.

9. Yasnoff WA, Overhage JM, Humphreys BL and Laventure M. Journal of the American Medical Informatics Association, 2001. 8 (6)

10. Hersh W, Margolis A, Quirós F, and Otero P. Building A Health Informatics Workforce In Developing Countries. Health Affairs, 2010. 29(2):274-277 